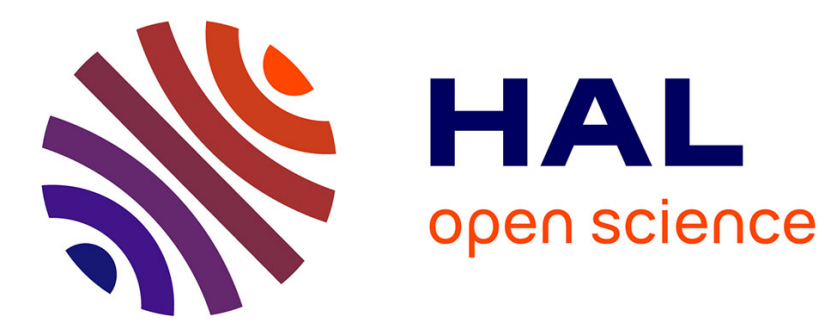

\title{
Removal of a mediastinal osteosynthesis screw by rigid bronchoscopy
}

\author{
J.-M. Vergnon, J. Huppert
}

\section{To cite this version:}

J.-M. Vergnon, J. Huppert. Removal of a mediastinal osteosynthesis screw by rigid bronchoscopy. Respiratory Medicine and Research, 2019, 75, pp.29 - 31. 10.1016/j.resmer.2019.02.001 . hal-03486621

\section{HAL Id: hal-03486621 \\ https://hal.science/hal-03486621}

Submitted on 20 Dec 2021

HAL is a multi-disciplinary open access archive for the deposit and dissemination of scientific research documents, whether they are published or not. The documents may come from teaching and research institutions in France or abroad, or from public or private research centers.
L'archive ouverte pluridisciplinaire HAL, est destinée au dépôt et à la diffusion de documents scientifiques de niveau recherche, publiés ou non, émanant des établissements d'enseignement et de recherche français ou étrangers, des laboratoires publics ou privés.

\section{다)(1) $(5$}

Distributed under a Creative Commons Attribution - NonCommercial| 4.0 International 


\title{
Removal of a mediastinal osteosynthesis screw by rigid bronchoscopy
}

\author{
Jean Michel Vergnon MD, PhD ${ }^{1,2,3}$ and Jean Huppert MD ${ }^{4,5}$
}

1-Department of chest diseases and thoracic oncology, University hospital of St Etienne 42055 St Etienne France

2- UMR INSERM 1059 «Sainbiose » Université de Lyon, université Jean Monnet St Etienne UFR de médecine Campus Santé Innovations, 10 rue de la Marandière 42270 St Priest en Jarez

2- President of the international French speaking group of thoracic endoscopy (GELF). 3-Neuro-surgical unit, Clinique du Parc 42270 St Priest en Jarez France.

4- President of the French Spine Society (SFCR)

\section{Declaration of conflicting interests :}

The authors declared no potential conflicts of interest with respect to the research, authorship, and/or publication of this article.

\section{Funding :}

The authors received no financial support for the research, authorship, and/or publication of this article.

Patient agreement : The patient has given his agreement for this publication

Key words : rigid bronchoscopy, foreign body, mediastinum, osteosynthesis, myeloma. 


\section{$\underline{\text { Introduction }}$}

To remove a foreign body from the tracheobronchial tree is a common job for bronchoscopists. Yet, to extract an extra-tracheal foreign body by bronchoscopy is exceptional and, to the best of our knowledge, never reported. We herein report a case of a patient who after vertebral surgical fixation presented with acute cough revealing a screw migrated to the mediastinum, touching the posterior tracheal wall.

\section{Case Report}

A 43 year-old male patient, suffered from a diffuse myeloma with complete osteolysis of the $7^{\text {th }}$ cervical vertebra, underwent an autogenic bone graft coupled with an osteosynthesis, considering the high risk of spinal cord injury. The osteosynthesis anterior plate was fixed between the $6^{\text {th }}$ cervical vertebra (C6) and the first thoracic vertebra (T1), using 6 screws. T1 was however invaded also by the myeloma and the fixation of one screw could not be secure enough in T1. Due to anatomical limitation of the exposure, this lower screw was fixed mostly in the disc $\mathrm{T} 1 / \mathrm{T} 2$ and consequently, prone to migration. After fixation, the patient underwent chemotherapy, external irradiation on lytic lesions with bone marrow transplantation.

One year later, the disease was controlled and the bone graft was consolidated. However, the patient presented with chronic cough and a slight dysphagia. A radiography followed by a computed tomography showed a screw dislodgment, migrated just behind the pars flaccida of the trachea (Figure 1a,b) neighboring the esophagus. The esophagus endoscopy was unremarkable, but bronchoscopy showed a bulging of the pars flaccida, without any ulceration, due to the screw (figure 2). Due to the position of the screw, close to the posterior membrane, a bronchoscopic extraction was judged less aggressive than an open 
surgical procedure, more complex in that location, behind the trachea and in the cervical/thoracic junction, at the upper part of the mediastinum. Therefore a decision of an endotracheal attempt was retained, and the patient underwent a rigid bronchoscopy procedure under general anesthesia.

During the procedure, the intact pars flaccida was first cut with scissors, then, the head of the screw was progressively extracted using a forceps and a lasso (Figure 3). Finally, the $1.5 \mathrm{~cm}$ long screw was extracted in totality through the tracheal wall (figure $4 \mathrm{a}$ ). After the screw removal, the posterior tracheal wall appears irregular and lacerated but without opened fistula (Figure 4b). A large antibiotic prophylaxis with Rifampicine $600 \mathrm{mg}$ and Levofloxacine $500 \mathrm{mg}$ was given for 2 weeks, starting first intravenously during the rigid bronchoscopy. Patients' symptoms have dramatically improved after the screw extraction and a bronchoscopy performed one month later showed no laceration of the pars flaccida (Figure 4c). Two years after the procedure the patient was still asymptomatic.

\section{$\underline{\text { Discussion }}$}

To the best of our knowledge, this procedure of extra-tracheal foreign body removal has been never published. To extract this screw through the tracheal posterior wall requires performing an intentional tracheal injury. Tracheal membrane rupture is well known after aggressive intubation, often with very large dehiscence. A spontaneous healing is often observed ${ }^{1}$ and we have expected and observed the same evolution.

Anterior cervical spine fixation is an effective procedure but some complications can occur such as migration of plates or screws. Lowery and McDonough ${ }^{2}$ reported a 35\% incidence of hardware failure but only $5 \%$ of these patients required hardware removal, and no esophageal complications were noted in these series. Most cases of migration have a rather 
benign clinical course. Yet, several cases of esophageal or pharyngeal perforations have been reported from few days to 11 years after cervical spine plating ${ }^{3,4}$.

In general, the airways are less affected by these migrations, due to the bigger distance from the spine. In 2005, Wong ${ }^{5}$ reported the first case of acute airway obstruction due to the migration of a screw causing a cervical abscess with airway compression. Only 5 authors report cases with screw migration in the trachea. In the first case of screw endotracheal migration 10 years after an osteosynthesis, fistula was surgically treated ${ }^{6}$.

In the second case ${ }^{7}$, ten months after cervical spine plating, a screw was found in the right lower lobe and extracted bronchoscopically but no fistula or perforation was seen. In the third case ${ }^{8}$, an ulceration of the trachea was observed by a migrating plate, few weeks after surgery. This tracheal fistula was closed also surgically. In the same observation, one screw found in the right lower lobe was removed by flexible bronchoscopy.

In the forth observation ${ }^{9}$, a screw was found in the right lower lobe, 5 years after an anterior plate fixation for retrolystesis; the screw was extracted by wedge resection. The migration through the tracheal wall was never been confirmed and the authors postulate that the screw could be inhaled after pharyngo-esophageal migration. The last case ${ }^{10}$ concerned a screw found in the intermediate bronchus, extracted with a rigid bronchoscope. This screw came from an anterior cervical plate fixed 10 years ago, eroding the trachea.

To conclude, our case is the first case of extraction through the tracheal wall with a rigid bronchoscope of a screw migrated in the mediastinum, in close relation with the posterior wall of the trachea, after a surgical procedure of vertebral fixation. 


\section{References}

1 Conti M. Fournier C, Hysi I, Ramon PP, Wurtz A. Conservative management of postintubation tracheal membrane ruptures. Intensive Care Med. 2010 ;36 (9):1622-3.

2 Lowery GL, McDonough RF. The significance of hardware failure in anterior cervical plate fixation. Patients with 2- to 7-year follow-up. Spine (Phila Pa 1976) 1998; 23:181-186; discussion 186-187

3 Cagli S, Isik HS, Zileli M. Cervical screw missing secondary to delayed esophageal fistula: case report. Turk Neurosurg 2009; 19:437-440

4 Kuo YC, Levine MS. Erosion of anterior cervical plate into pharynx with pharyngotracheal fistula. Dysphagia 2010; 25:334-337

5 Wong DT, Fehlings MG, Massicotte EM. Anterior cervical screw extrusion leading to acute upper airway obstruction: case report. Spine (Phila Pa 1976) 2005; 30:E683-686

6 Aydin K, Cokluk C, Kocabicak E, et al. Cervical screw extrusion into the trachea leading to perforation: a case report Chirurgia 2012; 25:355-357

7 Wu TK, Chung OM. Chung Dislodgement of a Screw to the Bronchial Tree After Anterior Cervical Plating Surgery. Journal of Orthopaedics, Trauma and Rehabilitation 2013; 17:106-108

8 Pariyadath A, Pathak V, Shojaee S. Tracheal Perforation by an Anterior Cervical Fixation Device. Chest 2015; 148:839A

9 Hung CC, Guo JH, Cheng YK, et al. Delayed anterior cervical screws migrating simultaneously to the lung and stomach. Spine J 2016; 16:e263-264

10 Demirkaya A, Ersen E, Kilic B. Wandering cervical screw: from cervical vertebra to intermediate bronchus. Asian Cardiovasc Thorac Ann 2016; 24:827-828

\section{Comments of figures}

Figure 1 a,b : migration of one screw, discovered one year after the plating. The screw is located between the posterior wall of the trachea (pars flaccida) and the esophagus

Figure 2 : The bulging pars flaccida, intact, without any fistula, prior to the incision.

Figure 3 : the different phases of the extraction with first incision of the bulging pars flaccida, then progressive extraction of the screw using forceps and lasso wire. 
Figure 4 a,b,c: The extracted screw of $15 \mathrm{~mm}$ in length (a), the final aspect of the pars flaccida just at the end of the extraction showing an irregular and lacerated membrane without open fistula (b) and the complete healing, seen here with a flexible bronchoscope, one month after the extraction (c). 

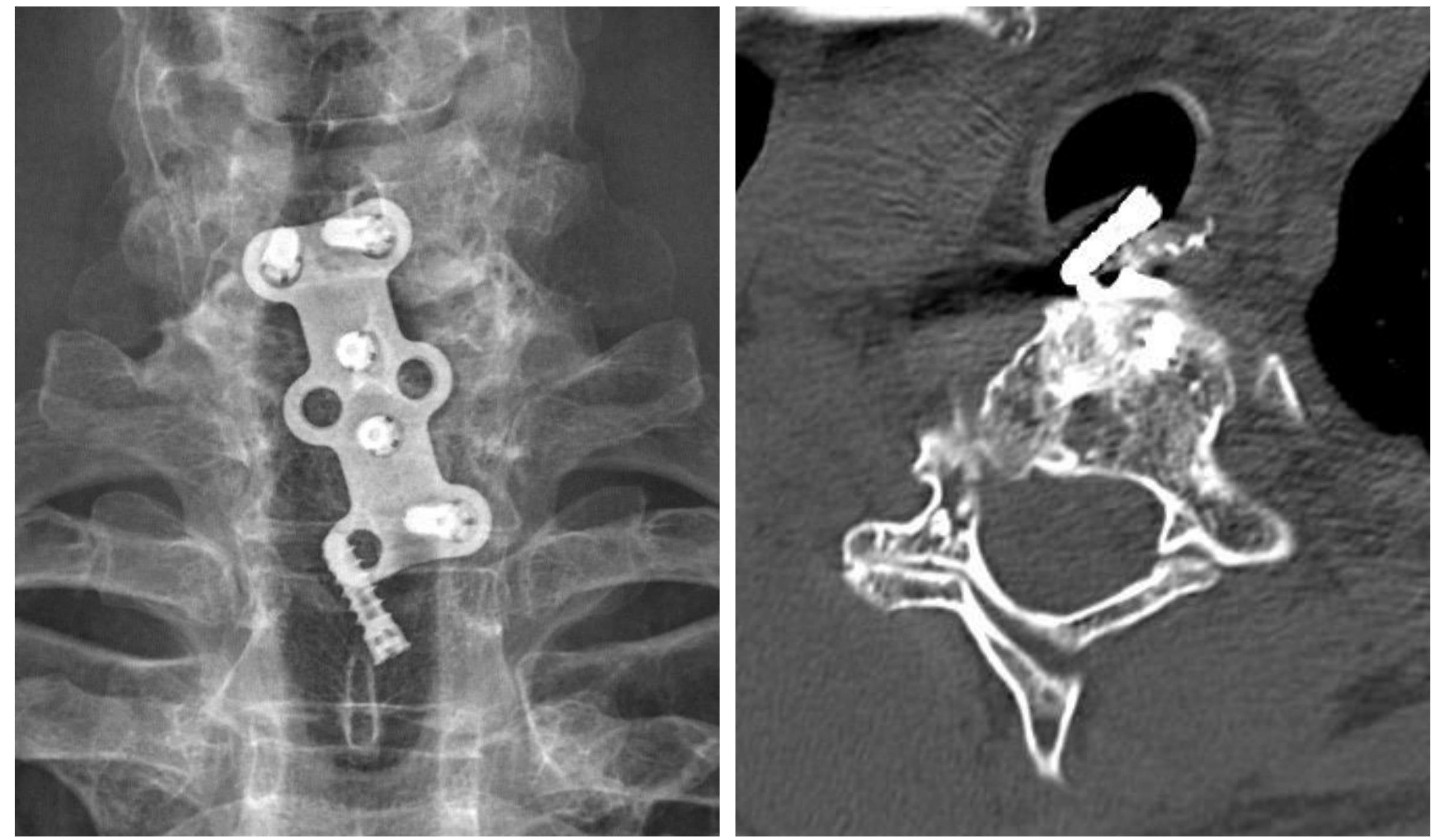

Figure 1 


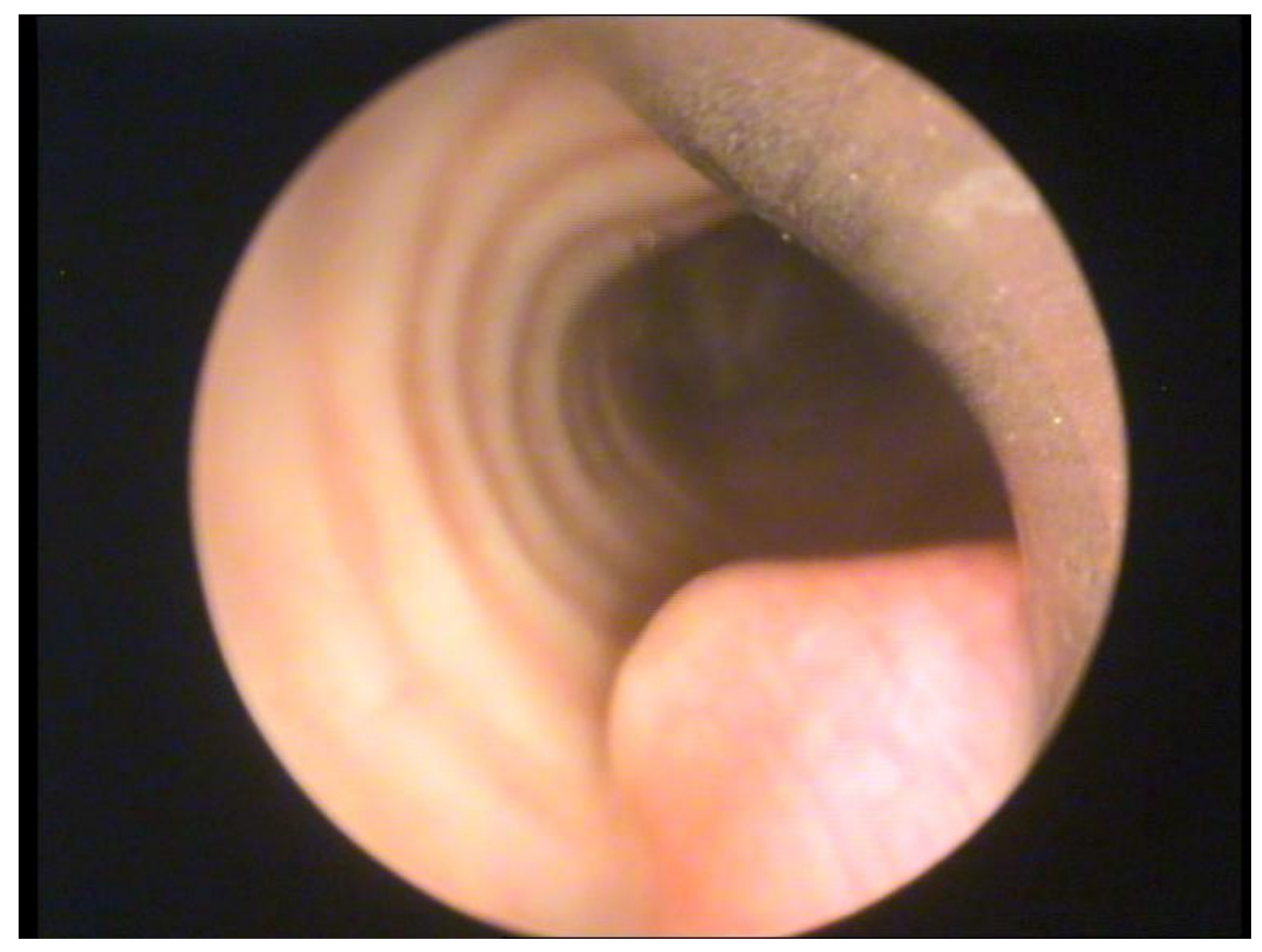

Figure 2 

Figure 4

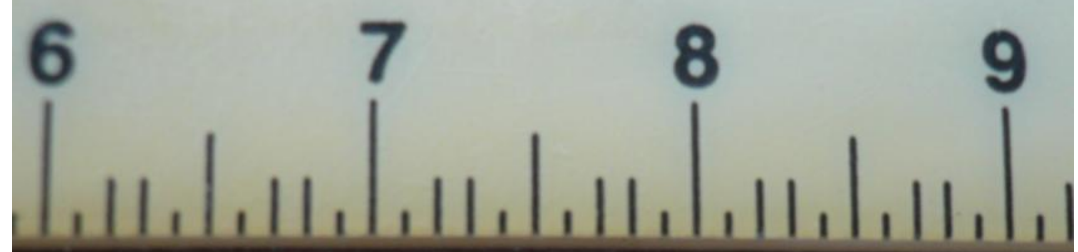

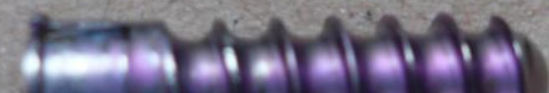

7

$X H \perp N \exists d$

바 $0 L \mathrm{~S}$ - 93 